\title{
Effects of Rhizosphere Oxygen Concentration on Rooting Ability of Machine-Transplanted Rice Seedling Before 3-leaf Stage
}

\section{Jing Chen ${ }^{1 *}$, Chaoyun Wang ${ }^{2}$, Yongjian $\mathrm{Yi}^{2}$, Hongying Wang ${ }^{2}$, Wanlai Zhou $^{1,3}$ and Zhenxie Yi $^{1}$ \\ ${ }^{1}$ College of Agronomy, Hunan Agricultural University, Changsha, China \\ ${ }^{2}$ Institute of Bast Fiber Crops, Chinese Academy of Agricultural Sciences, Changsha, China}

${ }^{3}$ Institute of Urban Agriculture, Chinese Academy of Agricultural Sciences, Chengdu, China

*Corresponding Author: Jing Chen, College of Agronomy, Hunan Agricultural University, Changsha, China.
Received: September 23, 2021

Published: November 25, 2021

(C) All rights are reserved by Jing Chen., et al.

\begin{abstract}
Rooting ability is an important trait that represents the quality of machine transplanted rice seedling. It is closely associated with the soluble sugar content in seedling and rhizosphere oxygen concentration may have a significant effect on rooting ability of rice seedling before 3-leaf stage. In this study, we used rice seedlings before 3-leaf stage as materials. The growth, soluble sugar content and rooting ability of rice seedlings under low oxygen ( $\left.0.1-1 \mathrm{mg} \cdot \mathrm{L}^{-1}, \mathrm{LO}\right)$, medium oxygen ( 4 - $5 \mathrm{mg} \cdot \mathrm{L}^{-1}$, MO), and high oxygen (7 - 8 $\mathrm{mg} \cdot \mathrm{L}^{-1}, \mathrm{HO}$ ) were investigated. The results showed that oxygen concentration had a significant effect on dry matter weight of rice seedlings and the differences among treatments varied as the leaf age increased. In all leaf ages, rice seedlings in MO had the lowest shoot soluble sugar content and the highest root soluble sugar content. At 1-leaf stage, the total length of new roots in the low oxygen treatment (LO) was $3.86 \mathrm{~cm}$ and $5.78 \mathrm{~cm}$ longer than that in $\mathrm{MO}$ and high oxygen (HO), respectively; and the number of new roots in LO was 0.83 and 0.87 higher than that in MO and HO, respectively. However, at 3-leaf stage, the total length of new roots in MO was $3.33 \mathrm{~cm}$ longer than that in LO, while that in LO was $3.18 \mathrm{~cm}$ longer than in the HO. Our study showed that when the duration is longer than one leaf age, rice seedlings under medium oxygen concentration had the strongest rooting ability. Like LO stress, HO treatment may also be a type of stress to rice seedlings, and its adverse effect on rice seedlings gradually appeared with prolonged treatment duration. This study can provide guidance for cultivating rice seedlings with high rooting ability based on rhizosphere oxygen concentration regulation.
\end{abstract}

Keywords: Rice; Rooting ability; Soluble Sugar; Hypoxia; Hyperoxia

\section{Introduction}

Rice is the main food source for over half of the world's population [1]; the planting area of rice accounts for over $12 \%$ of the farmland area in the world [2]. China is the main rice cultivation country with over 30 million hectares of rice cultivation, which is $18.6 \%$ of the rice cultivation area in the world [3]. With the aging of the population, the rural labor force continues to decline, and machine transplantation has become the ultimate choice to replace manual transplantation [4]. In mechanical transplanting practices, seedlings transplanted before tillering (about 3-leaf stage) usually undergo "transplantation shock" in which phase the growth of transplanted seedlings becomes stagnant for several days but invests its energy to establish a new root system. Only when new

Citation: Jing Chen., et al. "Effects of Rhizosphere Oxygen Concentration on Rooting Ability of Machine-Transplanted Rice Seedling Before 3-leaf Stage". Acta Scientific Agriculture 5.12 (2021): 31-40. 
roots grow, new tillers begin to emerge [5]. Therefore, the initiation and growth of new roots directly affect the emergence of new tillers of mechanically transplanted rice in the field and has a large impact on grain yield. Rooting ability is usually used to assess the ability of rice seedlings to form and grow new roots after transplantation. In detail, it is represented by parameters including total length, total number, and total weight of new roots developed by root-cut rice seedling after 3-7 days of cultivation in water [6]. Many field experiments have provided evidence that rooting ability in the seedling stage is positively correlated with post-transplantation root vigor, effective panicle number, and yield of rice [7-9]. So, it is necessary to study the factors that affect the rooting ability in depth.

Soluble sugars (sucrose, glucose, and fructose) play important roles in maintaining plant growth and development $[10,11]$. The direct contact of aerial tissues with sucrose in the growth medium is necessary and sufficient for inducing lateral root formation in Arabidopsis grown in the medium [12]. Exogenous sucrose, glucose, and fructose can induce the formation and promote the elongation of adventitious roots. Meanwhile, the regulation of sugars in adventitious root formation is related to sugar concentration; high concentration of sugar in the medium can often inhibit root formation $[13,14]$. In barley root, the accumulation of glucose and sucrose eliminated the inhibitory effect of environmental stress, thereby maintaining the development of lateral roots under osmotic stress [15]. Studies on rice seedling showed that the increase in rooting ability was often accompanied by the increase in soluble sugar content, suggesting that soluble sugar may play an important role during rice root formation $[16,17]$. In rice seedlings under 24 hours of continuous light, the soluble sugar content drastically increased and no significant changes were detected in other substances, in the meantime, the rooting ability significantly increased, which further showed that plant soluble sugar content was the key factor determining the rooting ability of rice seedling [18].

The environment significantly affects soluble sugar in plants. Changes in environmental factors, such as light, water, and temperature, affect the photosynthetic efficiency in leaves (source), thereby influencing the amount of soluble sugar provided for sink tissues [19]. In addition, changes in the environment can usually lead to changes in the partition of sugar between source and sink [20]. Generally, under drought, salt, low temperature, and flooding stress, the soluble sugar concentration in leaves increases, while high light irradiance, heavy metals, nutrient deficiency, and ozone decrease the concentration of soluble sugar in leaves [19]. Oxygen in rhizosphere is an important environmental factor that affects the physiology and metabolism of rice root [21,22]. Under hypoxia stress, respiration in roots and photosynthesis in leaves are both inhibited; energy metabolism becomes imbalanced, causing drastic changes in the sugar content of plants [23]. Although the aerenchyma in rice seedling begins to form at the beginning of root formation [24], the complete aerenchyma is not formed until 3-leaf stage [25]. Before this point, there is no passage for oxygen to flow downward in the seedling. Oxygen in the rhizosphere is an important oxygen source for root respiration. Therefore, its effect on sugar in rice seedling before 3-leaf stage may be especially significant.

In the last few decades, studies on rhizosphere oxygen of rice mostly focused on short-term hypoxic or anoxic stress, and only a few of researchers have tried to apply active aeration in rice cultivation [22]. Xu., et al. [26] found that the effects of low oxygen stress on root functions and nitrogen metabolism-related enzymes activities varied with treatment duration, which suggested that the short-term effect of oxygen treatment on rice seedlings may be significantly different from the long-term effect. Since rhizosphere oxygen may significantly affect soluble sugar in rice seedling before 3-leaf stage, and the soluble sugar content is a key factor affects rice rooting ability, rhizosphere oxygen concentration may have a significant effect on the rooting ability of rice seedling before 3-leaf stage. In this way, it's possible to regulate the rooting ability of rice seedling by rhizosphere oxygen concentration. However, there are few research reports on this aspect so far.

In this study, we used rice seedlings before 3-leaf stage as materials. The growth, soluble sugar content and rooting ability of rice seedlings under low oxygen $\left(0.1-1 \mathrm{mg} \cdot \mathrm{L}^{-1}, \mathrm{LO}\right)$, medium oxygen (4 - $\left.5 \mathrm{mg} \cdot \mathrm{L}^{-1}, \mathrm{MO}\right)$, and high oxygen (7 - $\left.8 \mathrm{mg} \cdot \mathrm{L}^{-1}, \mathrm{HO}\right)$ were investigated. Our purpose was: (1) to investigate the effects of rhizosphere oxygen on the rooting ability of rice seedling in a wide range of oxygen concentration; (2) to clarify the relationship between these effects and the oxygen treatment duration, thereby providing a reference for cultivating rice seedlings with high rooting ability.

\section{Methods and Materials}

The experiment was conducted in the Institute of Bast Fiber Crops, Chinese Academy of Agricultural Sciences in December 
2019. Rice was grown hydroponically. The nutrient solution was prepared as the formulation from the International Rice Research Institute. Hydroponic tanks were $40 \mathrm{~cm} \times 26 \mathrm{~cm} \times 25 \mathrm{~cm}$ (length $\times$ width $\times$ height). The rice variety used in the study was ' $Y$ Liangyou 957', a variety widely cultivated in Hunan.

\section{Treatments and methods}

Rice seeds were sterilized in 75\% ethanol, soaked for 2 days, and germinated at $30^{\circ} \mathrm{C}$. Well germinated seeds were selected and placed in the planting cubes with an opening in the middle, with 3 seeds in each cube, and then placed in the holes on the planting board. There were 42 cubes in each planting board. Hydroponic tanks were placed in the growth chamber $\left(25^{\circ} \mathrm{C}\right.$ Day $/ 15^{\circ} \mathrm{C}$ night $)$. White LED lights were used as a light source, with a light intensity of $200 \mu \mathrm{mol} \cdot \mathrm{m}^{-2} \cdot \mathrm{s}^{-1}$. Twelve hours of light was provided per day. Seedlings were cultured with water for the first 3 days. From the 4 th day, they were cultured with nutrient solution, and treatments with different oxygen concentrations began at the same time.
A total of 3 treatments were established, including low oxygen (0.1 - $\left.1 \mathrm{mg} \cdot \mathrm{L}^{-1}, \mathrm{LO}\right)$, medium oxygen ( 4 - $\left.5 \mathrm{mg} \cdot \mathrm{L}^{-1}, \mathrm{MO}\right)$, and high oxygen ( 7 - $8 \mathrm{mg} \cdot \mathrm{L}^{-1}, \mathrm{HO}$ ). Each treatment was repeated three times; a total of 9 hydroponic tanks were used. In LO and MO treatments, nitrogen was released into the nutrient solution through a timer-controlled electromagnetic valve to reduce the oxygen concentration in the nutrient solution. Nitrogen was released every $4.5 \mathrm{~h}$ in LO for $4.5 \mathrm{~min}$ each time, and every $12 \mathrm{~h}$ in MO for $0.5 \mathrm{~min}$ each time. In HO treatment, air was pumped into the nutrient solution through an air pump (SOBO, SB-988) to maintain the oxygen concentration in the nutrient solution. During the experiment, hydroponic tanks were fully filled with nutrient solution, to prevent a gap forming below the planting board, which could result in unexpected oxygen supply to rice seedling roots. An optical fiber oxygen meter (FS $\mathrm{O}_{2}-4$, PyroScience) was used to continuously measure the oxygen concentration in the nutrient solution (Figure 1). Nutrient solution was not replaced during the experiment; $\mathrm{pH}$ values were adjusted to 5.0-6.0 using diluted hydrochloric acid or $\mathrm{NaOH}$ every day.

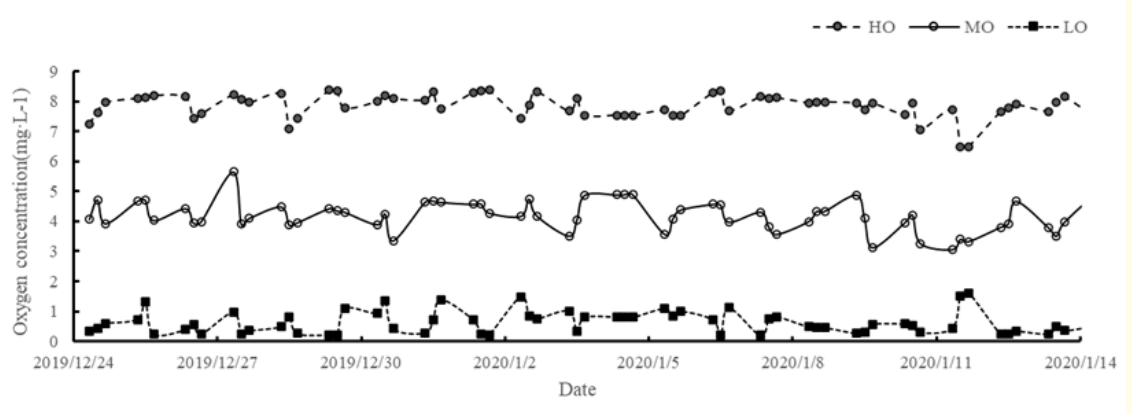

Figure 1: Oxygen Concentrations during the Experiment.

\section{Measurement of the parameters}

Ten planting cubes (30 seedlings in total) were randomly selected from each treatment at 1-, 2-, and 3-leaf stage. Sponges were carefully removed, and the separated rice seedlings were used for further analysis and measurement.

Plant height, maximum root length, dry matter weight, soluble sugar content, and nitrate nitrogen content

Ten seedlings were selected, and excess water on the surface was removed with tissue. Seedlings were placed horizontally on the scanner, with the root system spread out sufficiently, and seedling scanned images were obtained. Plant height was calculated using Image-Pro Plus 6.0, and the maximum root length was calculated using Root Nav [42]. Shoot and root were separated from the stem base and placed in a baking oven at $105^{\circ} \mathrm{C}$ for deactivation for $0.5 \mathrm{~h}$ and dried at $80^{\circ} \mathrm{C}$ until reaching a constant weight. The dry matter weight of the shoot and root was recorded, and samples were preserved for the measurement of soluble sugar and nitrate nitrogen content. Soluble sugar content was determined using the phenolsulfuric acid method [43]; nitrate nitrogen content was measured using the salicylic acid method [43]. 
Plant soluble protein content, chlorophyll content, and root activity

Ten seedlings were selected and separated as shoot and root from the stem base. The shoot was used for measuring the content of plant soluble proteins and chlorophyll; the root was used for the measurement of root activity. The Coomassie Brilliant Blue G-250 method was used to determine the plant soluble protein content [43]. Chlorophyll content was measured by $95 \%$ ethanol extraction and spectrophotometry [43]. TTC method was used to determine root activity [43].

\section{Rooting ability}

Ten seedlings were selected, and all roots were removed from the root base. They were planted in water in the growth chamber, with $12 \mathrm{~h}$ light, at $25^{\circ} \mathrm{C}$ (light) $/ 15^{\circ} \mathrm{C}$ (dark). Three days later, seedlings were laid out on the scanner to fully spread out the root system. Images of seedling morphology were obtained from the scanner. Root Nav software was used to determine the length and number of the newly developed roots [42].

Data analysis

SAS 8.2 and Excel 2016 were used to analyze data and generate graphs. The differences among treatments were analyzed using ANOVA; correlation analysis among parameters was conducted in CORR.

\section{Results}

Dry matter weight, plant height, plant soluble protein, and chlorophyll content in rice seedlings

As shown in table 1, oxygen concentration had a significant effect on dry matter weight of rice seedlings; the differences among treatments changed as the leaf age increased. At 1-leaf stage, the dry matter weight of shoot increased with increasing oxygen concentration, where that in the HO treatment increased by $24.2 \%$ and $18.1 \%$ compared to that in LO and MO, respectively. The dry matter weight of root also increased with increasing oxygen concentration, but there was no significant difference among treatments. The root/shoot ratio in $\mathrm{HO}$ was significantly lower than that in MO and LO. At 2-leaf stage, the dry matter weight of shoot in HO was 24.6\% and $16.7 \%$ higher than that in LO and MO, respectively, while that in $\mathrm{HO}$ was $15.7 \%$ and $9.3 \%$ higher than that in LO and MO, respectively. At 3-leaf stage, the dry matter weight of rice seedlings did not increase with increasing oxygen concentration; the dry matter weight of shoot, root, and the root/shoot ratio of rice seedlings among treatments did not exhibit significant differences. At each leaf age, there was no significant difference in plant height, plant soluble protein content, and chlorophyll content among different treatments.

\begin{tabular}{|c|c|c|c|c|c|c|c|}
\hline $\begin{array}{l}\text { Leaf } \\
\text { age }\end{array}$ & $\begin{array}{l}\text { Treat- } \\
\text { ment }\end{array}$ & $\begin{array}{l}\text { Dry matter weight of } \\
\text { shoot (mg-plant 1) }\end{array}$ & $\begin{array}{l}\text { Dry matter weight } \\
\text { of root (mg-plant } 1 \text { ) }\end{array}$ & $\begin{array}{l}\text { Root } / \text { shoot } \\
\text { ratio }\end{array}$ & $\begin{array}{l}\text { Plant height } \\
\text { (cm) }\end{array}$ & $\begin{array}{l}\text { Soluble pro- } \\
\text { tein }\left(\mathrm{mg} \cdot \mathrm{g}^{-1}\right)\end{array}$ & $\begin{array}{c}\text { Chlorophyll } \\
\text { (mg·g-1) }\end{array}$ \\
\hline \multirow{2}{*}{$\begin{array}{l}\text { 1-leaf } \\
\text { stage }\end{array}$} & LO & $7.47 \pm 0.24 b$ & $2.09 \pm 0.07 a$ & $0.28 \pm 0.01 \mathrm{a}$ & $8.09 \pm 0.88 \mathrm{a}$ & $10.82 \pm 0.16 a$ & $1.25 \pm 0.10 \mathrm{a}$ \\
\hline & $\mathrm{HO}$ & $9.28 \pm 0.56 a$ & $2.31 \pm 0.13 a$ & $0.25 \pm 0.01 b$ & $9.67 \pm 1.13 a$ & $11.01 \pm 0.70 \mathrm{a}$ & $1.26 \pm 0.18 \mathrm{a}$ \\
\hline \multirow{2}{*}{$\begin{array}{l}\text { 2-leaf } \\
\text { stage }\end{array}$} & LO & $20.29 \pm 1.76 b$ & $4.46 \pm 0.12 b$ & $0.22 \pm 0.01 \mathrm{a}$ & $15.90 \pm 0.84 a$ & $11.02 \pm 0.42 \mathrm{a}$ & $1.79 \pm 0.17 \mathrm{a}$ \\
\hline & $\mathrm{HO}$ & $25.29 \pm 0.93 a$ & $5.16 \pm 0.13 a$ & $0.20 \pm 0.00 \mathrm{a}$ & $16.03 \pm 2.08 \mathrm{a}$ & $11.78 \pm 2.35 a$ & $1.49 \pm 0.19 a$ \\
\hline \multirow{3}{*}{$\begin{array}{l}\text { 3-leaf } \\
\text { stage }\end{array}$} & $\mathrm{LO}$ & $53.13 \pm 8.72 a$ & $11.27 \pm 1.59 a$ & $0.22 \pm 0.05 a$ & $25.50 \pm 0.22 a$ & $10.94 \pm 1.12 \mathrm{a}$ & $1.68 \pm 0.20 a$ \\
\hline & MO & $55.69 \pm 1.53 a$ & $11.79 \pm 2.39 a$ & $0.21 \pm 0.04 \mathrm{a}$ & $25.14 \pm 2.58 a$ & $10.66 \pm 0.35 a$ & $1.76 \pm 0.21 \mathrm{a}$ \\
\hline & $\mathrm{HO}$ & $54.55 \pm 5.75 a$ & $11.02 \pm 3.60 a$ & $0.20 \pm 0.05 a$ & $25.97 \pm 1.37 a$ & $10.00 \pm 0.82 a$ & $1.79 \pm 0.23 a$ \\
\hline
\end{tabular}

Table 1: Dry matter weight, plant height, soluble protein content, and chlorophyll content in rice seedlings under different oxygen concentrations at different leaf ages.

Note: different letters in the same column at the same leaf age represent significant differences among treatments (Duncan test, $\alpha=0.05$ ). 
Soluble sugar and nitrate nitrogen content in rice seedlings

At each leaf age, there was no significant change in shoot soluble sugar content, which was between $40 \mathrm{mg} \cdot \mathrm{g}^{-1}-50 \mathrm{mg} \cdot \mathrm{g}^{-1}$ (Figure $2 \mathrm{~A}$ ). The root soluble sugar content drastically decreased from 2-leaf stage to 3-leaf stage; its average value decreased from $31.32 \mathrm{mg} \cdot \mathrm{g}^{-1}$ to $11.22 \mathrm{mg} \cdot \mathrm{g}^{-1}$ (Figure $2 \mathrm{~B}$ ). Although the differences among treatments were not significant, the variation pattern of soluble sugar content with oxygen concentration at each leaf age was similar. That is, the MO treatment had the lowest shoot soluble sugar content and the highest root soluble sugar content. Additionally, in all leaf stages, there was a significant negative correlation between the shoot and root soluble sugar content (1-leaf stage, $r_{1}=-0.86688, p$ $=0.0025 ;$ 2-leaf stage, $r_{2}=-0.91306, p=0.0006$; 3-leaf stage, $r_{3}=$ $-0.79491, p=0.0105$ ).
From 1-leaf stage to 3-leaf stage, the root nitrate nitrogen content gradually declined; its average value decreased from 4795.96 $\mu \mathrm{g} \cdot \mathrm{g}^{-1}$ to $3231.97 \mu \mathrm{g} \cdot \mathrm{g}^{-1}$ (Figure 2D). However, the shoot nitrate nitrogen content exhibited a drastic increase from 2-leaf stage to 3 -leaf stage, with its average value increasing from $877.98 \mu \mathrm{g}^{-1} \mathrm{~g}^{-1}$ to $1452.16 \mu \mathrm{g} \cdot \mathrm{g}^{-1}$ (Figure 2C). The shoot nitrate nitrogen content was not significantly different among treatments, but the root nitrate nitrogen content decreased as the oxygen concentration increased. In detail, at 1-leaf stage, the root nitrate nitrogen content in $\mathrm{HO}$ was $1011.63 \mu \mathrm{g} \cdot \mathrm{g}^{-1}$ and $592.01 \mu \mathrm{g} \cdot \mathrm{g}^{-1}$ lower than that in LO and MO, respectively; at 3-leaf stage, the root nitrate nitrogen content in $\mathrm{HO}$ was $563.61 \mu \mathrm{g} \cdot \mathrm{g}^{-1}$ and $442.20 \mu \mathrm{g} \cdot \mathrm{g}^{-1}$ lower than that in LO and MO, respectively (Figure 2D).
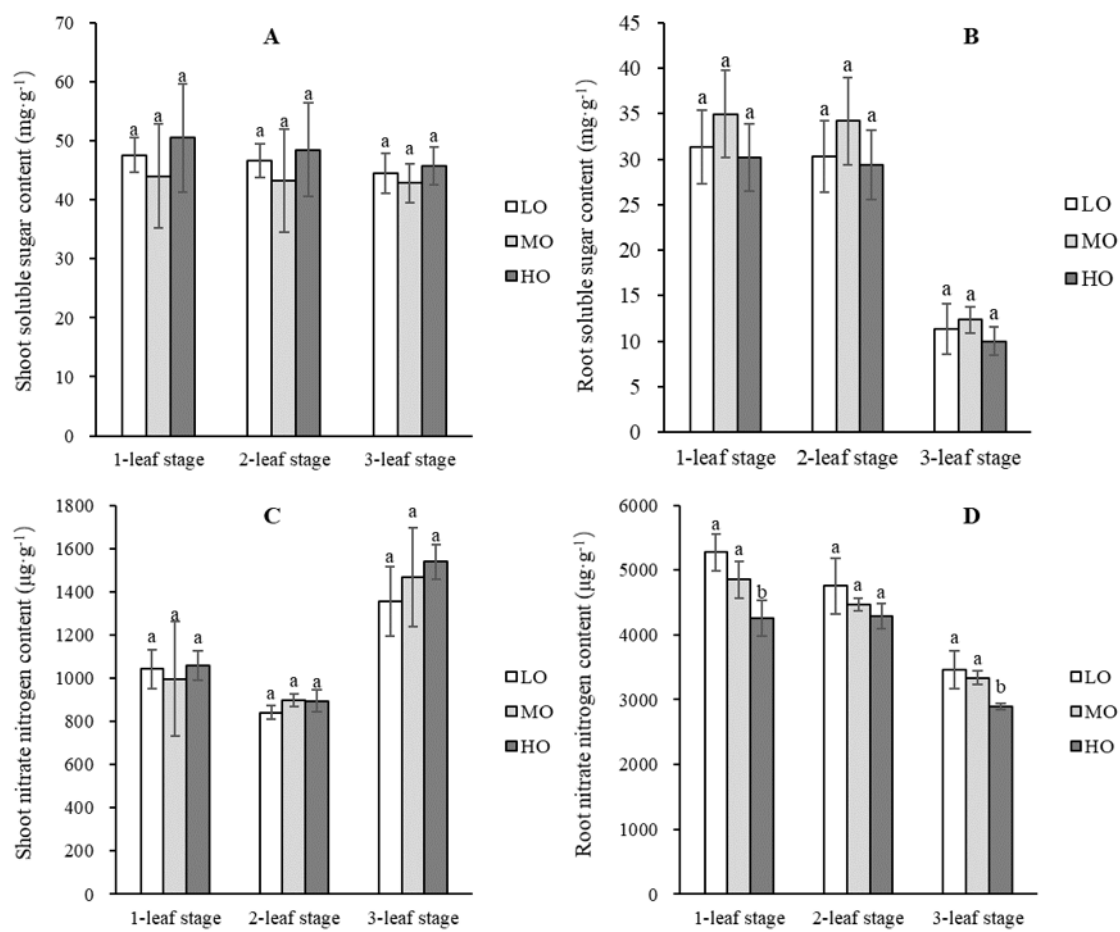

Figure 2: Soluble sugar and nitrate nitrogen content in rice seedlings under different oxygen concentrations at different leaf ages.

Note: Error bars represent SE $(n=3)$. Different letters at the same leaf age represent significant differences among treatments (by Duncan test, $\alpha=0.05$ ). 
Maximum root length, root activity, and rooting ability

From 1-leaf stage to 2-leaf stage, the maximum root length of rice seedlings drastically increased; the average value increased to $13.07 \mathrm{~cm}$ from $1.55 \mathrm{~cm}$ (Figure 3A). HO treatment significantly increased the maximum root length and differences among treatments became more significant with the increase of leaf age. At 2-leaf stage, the maximum root length was not significantly different among treatments. At 3-leaf stage, the maximum root length in $\mathrm{HO}$ was $1.74 \mathrm{~cm}$ and $2.29 \mathrm{~cm}$ higher than that in $\mathrm{MO}$ and $\mathrm{LO}$, respectively. At 3-leaf stage, the maximum root length in $\mathrm{HO}$ was $2.32 \mathrm{~cm}$ higher than that in MO, while that in MO was $2.38 \mathrm{~cm}$ higher than that in LO.

From 2-leaf stage to 3-leaf stage, the root activity of rice seedlings significantly increased; its average value increased to 32.87 from $23.06 \mu \mathrm{g} \mathrm{TTF} \cdot \mathrm{g}^{-1} \cdot \mathrm{h}^{-1}$ (Figure 3B). At 1-leaf stage and 2-leaf stage, the root activity was not significantly different among treatments. At 3-leaf stage, the root activity in HO was significantly higher than that in MO and HO, with a $20.9 \%$ and $34.9 \%$ increase, respectively.

The oxygen concentration significantly affected the rooting ability of rice seedlings; the difference among treatments changed as leaf age increased (Figure 3C-D). At 1-leaf stage, the total length of new roots in $\mathrm{LO}$ was $3.86 \mathrm{~cm}$ and $5.78 \mathrm{~cm}$ longer than that in MO and HO, respectively, and the number of new roots in LO was 0.83 and 0.87 higher than that in $\mathrm{MO}$ and $\mathrm{HO}$, respectively. At 2-leaf stage, the total length and the number of new roots were not significantly different among treatments. At 3-leaf stage, the total length of new roots in MO was $3.33 \mathrm{~cm}$ longer than that in LO, while that in LO was $3.18 \mathrm{~cm}$ higher than that in HO. The number of new roots was not significantly different among treatments at the same stage.
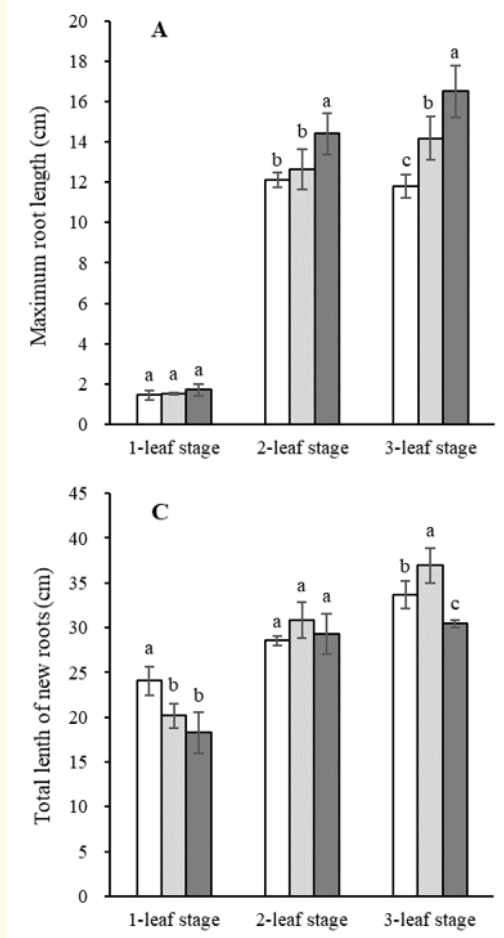

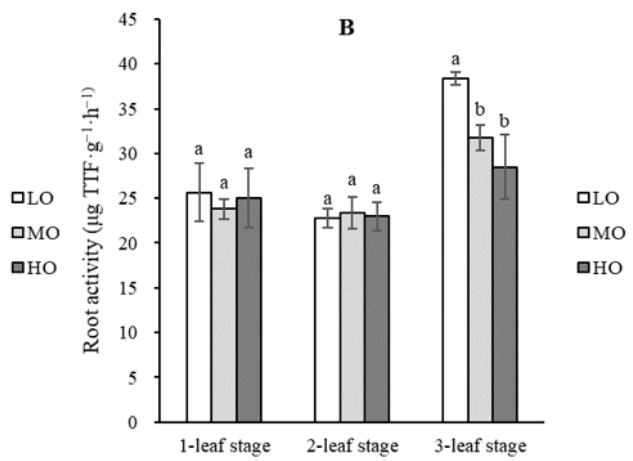

D

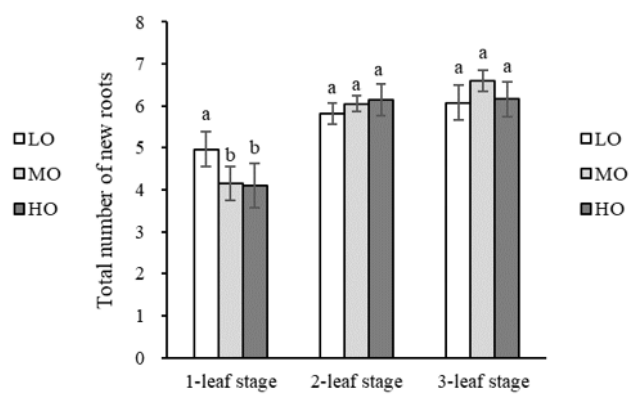

Figure 3: Maximum root length, root activity, and rooting ability of rice seedlings under different oxygen concentrations at different leaf ages.

Note: Error bars represent SE $(n=3)$. Different letters at the same leaf age represent significant differences among treatments (by Duncan test, $\alpha=0.05$ ). 
Correlation of soluble sugar content, nitrate nitrogen content with maximum root length, root activity, and rooting ability

As shown in table 2, the maximum root length was closely related to the root nitrate nitrogen content; at 1-leaf stage and 3-leaf stage, there was a significant negative correlation between maximum root length and root nitrate nitrogen content of rice seedling. The root activity and total length of new roots were closely related to the soluble sugar content, especially the root soluble sugar con- tent. Specifically, at 2-leaf stage, there was a strong positive correlation between the root activity, the total length of new roots and the root soluble sugar content, and the positive correlation between the total length of new roots and the root soluble sugar content still existed at 3-leaf stage. At each leaf age, there was no significant correlation between the number of new roots and the shoot/root soluble sugar content or nitrate nitrogen content.

\begin{tabular}{|c|c|c|c|c|c|c|}
\hline Leaf age & & $\begin{array}{l}\text { Test sta- } \\
\text { tistic }\end{array}$ & $\begin{array}{c}\text { Maximum } \\
\text { root length }\end{array}$ & $\begin{array}{c}\text { Root } \\
\text { activity }\end{array}$ & $\begin{array}{l}\text { Total length } \\
\text { of new roots }\end{array}$ & $\begin{array}{l}\text { Total number } \\
\text { of new roots }\end{array}$ \\
\hline \multirow{8}{*}{ 1-Leaf stage } & \multirow{2}{*}{$\begin{array}{c}\text { Shoot soluble sugar } \\
\text { content }\end{array}$} & $\mathrm{r}$ & 0.5439 & -0.4828 & -0.4421 & 0.0915 \\
\hline & & $\mathrm{p}$ & 0.1301 & 0.1881 & 0.2334 & 0.8150 \\
\hline & \multirow{2}{*}{$\begin{array}{c}\text { Root soluble sugar } \\
\text { content }\end{array}$} & $\mathrm{r}$ & -0.3977 & 0.5386 & 0.4169 & 0.0353 \\
\hline & & $\mathrm{p}$ & 0.2891 & 0.1346 & 0.2643 & 0.9283 \\
\hline & \multirow{2}{*}{$\begin{array}{l}\text { Shoot nitrate nitro- } \\
\text { gen content }\end{array}$} & $\mathrm{r}$ & -0.1601 & 0.0525 & -0.0123 & -0.0208 \\
\hline & & $\mathrm{p}$ & 0.6808 & 0.8933 & 0.9749 & 0.9577 \\
\hline & \multirow{2}{*}{$\begin{array}{c}\text { Root nitrate nitrogen } \\
\text { content }\end{array}$} & $\mathrm{r}$ & -0.8162 & 0.3818 & 0.8666 & 0.4086 \\
\hline & & $\mathrm{p}$ & 0.0073 & 0.3107 & 0.0025 & 0.2749 \\
\hline \multirow{8}{*}{ 2-Leaf stage } & \multirow{2}{*}{$\begin{array}{c}\text { Shoot soluble sugar } \\
\text { content }\end{array}$} & $\mathrm{r}$ & 0.3166 & -0.7398 & -0.7733 & -0.3815 \\
\hline & & $\mathrm{p}$ & 0.4065 & 0.0227 & 0.0145 & 0.3110 \\
\hline & \multirow{2}{*}{$\begin{array}{l}\text { Root soluble sugar } \\
\text { content }\end{array}$} & $\mathrm{r}$ & -0.2163 & 0.8112 & 0.8484 & 0.4962 \\
\hline & & $\mathrm{p}$ & 0.5763 & 0.0080 & 0.0038 & 0.1743 \\
\hline & \multirow{2}{*}{$\begin{array}{l}\text { Shoot nitrate nitro- } \\
\text { gen content }\end{array}$} & $\mathrm{r}$ & 0.3348 & -0.2401 & 0.0835 & -0.0516 \\
\hline & & $\mathrm{p}$ & 0.3785 & 0.5338 & 0.8309 & 0.8951 \\
\hline & \multirow{2}{*}{$\begin{array}{c}\text { Root nitrate nitrogen } \\
\text { content }\end{array}$} & $\mathrm{r}$ & -0.5709 & 0.1198 & -0.2496 & -0.1609 \\
\hline & & $\mathrm{p}$ & 0.1084 & 0.7588 & 0.5173 & 0.6791 \\
\hline \multirow{8}{*}{ 3-Leaf stage } & \multirow{2}{*}{$\begin{array}{c}\text { Shoot soluble sugar } \\
\text { content }\end{array}$} & $\mathrm{r}$ & 0.1723 & 0.0851 & -0.5629 & -0.1089 \\
\hline & & $\mathrm{p}$ & 0.6576 & 0.8276 & 0.1146 & 0.7803 \\
\hline & \multirow{2}{*}{$\begin{array}{l}\text { Root soluble sugar } \\
\text { content }\end{array}$} & $\mathrm{r}$ & -0.3271 & 0.1129 & 0.7587 & 0.3828 \\
\hline & & $\mathrm{p}$ & 0.3903 & 0.7724 & 0.0178 & 0.3093 \\
\hline & \multirow{2}{*}{$\begin{array}{l}\text { Shoot nitrate nitro- } \\
\text { gen content }\end{array}$} & $\mathrm{r}$ & 0.4872 & -0.5507 & -0.3510 & 0.0837 \\
\hline & & $\mathrm{p}$ & 0.1835 & 0.1244 & 0.3544 & 0.8306 \\
\hline & \multirow{2}{*}{$\begin{array}{l}\text { Root nitrate nitrogen } \\
\text { content }\end{array}$} & $\mathrm{r}$ & -0.8229 & 0.7298 & 0.6620 & 0.1087 \\
\hline & & $\mathrm{p}$ & 0.0064 & 0.0256 & 0.0521 & 0.7806 \\
\hline
\end{tabular}

Table 2: Correlation analysis of plant soluble sugar and nitrate nitrogen content with maximum root length, root activity, and rooting ability of rice seedlings at different leaf ages.

\section{Discussion}

Generally, low oxygen in the rhizosphere is considered to severely affect rice growth and development $[21,27]$, while aeration treatment has the opposite effect $[28,29]$. However, this conclusion is mostly based on results measured at a single time point and lack of a comparison among multiple time points across a lon- 
ger time span. Results in this study showed that the response of rice seedlings to rhizosphere oxygen concentration changed with treatment duration. At 1-leaf and 2-leaf stage, the biomass of rice seedlings increased with the increasing rhizosphere oxygen concentration. However, at 3-leaf stage, rice seedling biomass in $\mathrm{HO}$ was not significantly different from those in LO and MO. At 1-leaf stage, root activity was not significantly different among different treatments, but at 3-leaf stage, the root activity of rice seedlings decreased with the increasing oxygen concentration. At 1-leaf stage, the rooting ability of rice seedlings in LO was significantly higher than those in MO and HO, while at 3-leaf stage, the rooting ability in MO was significantly higher than those in LO and HO. Our result is consistent with $\mathrm{Xu}$., et al. [26]. The reason for these changes may be that the effect of oxygen concentration on rice seedlings gradually appeared as treatment duration increased, or that the gradual development of aerenchyma tissue in rice roots reduced the need for rhizosphere oxygen. In the latter case, HO gradually became unnecessary and even became a stress. It's consistent with the conclusion by Hu., et al. [30] that higher rhizosphere oxygen concentration was not always better, and there was a threshold for oxygen concentration, and also consistent with the observations by other researchers [31,32].

In this study, the rooting ability of rice seedlings in different oxygen concentrations was significantly different, indicating that rhizosphere oxygen concentration significantly affected the rooting ability of rice seedlings before 3-leaf stage, consistent with our initial speculation. Nonetheless, such an effect did not seem to act directly through soluble sugar. First, although root soluble sugar content was positively correlated with rooting ability, roots were removed when the rooting ability was tested. Therefore, soluble sugar content in the root system should not directly affect rooting ability. Second, in this study, the rooting ability of rice seedlings was negatively correlated with shoot soluble sugar content, which contrasted with previous observations [16,17]. It's also different from the fact previously found by us that the increasing shoot soluble sugar content induced by light could eventually increase rooting ability [18]. However, we don't think it's contradictory. Under favorable conditions, the increase in photosynthesis in rice results in a high level of photosynthates and accumulation of soluble sugars (mainly sucrose). These soluble sugars not only can provide energy and substances for the rooting of plants, but also can regulate the development and growth of plant root systems as a signal [33,34], thereby increasing the rooting ability of rice. Soluble sugars also fully participate in plant responses to environmental stress [19]. Increase in soluble sugar content has been observed in rice leaves under stress conditions, such as drought [35], salt stress [36], and cadmium stress [37]. In this study, the increase in shoot soluble sugar content in rice seedlings under LO and HO may be the responses to stress.

Because plants need energy and resources to respond to stress, the source-sink partition among different organs is a key component in the mechanism of plant adaptation to stress [19]. Under drought and salt stress, soluble sugar content in the aboveground and underground portions of rice increased simultaneously $[35,36]$. Research by Xu., et al. [35] showed that under environmental stress, it was very possible that the transport of photosynthates from source to sink was promoted by adjusting the activity of SPS and Inv in the source and sink organs. Low oxygen inhibited the transport of soluble sugar from endosperm to the coleoptile in barley, oat, and rice [38]. Nevertheless, plants follow quite different response pattern to different stressors [19]. In this study, in LO and HO treatment, the shoot soluble sugar content was higher than that in MO, but the root soluble sugar content was lower than that in MO, suggesting that rhizosphere oxygen concentration may have affected the partitioning of assimilates between shoot and root. The LO and HO treatment may have inhibited the transport of assimilates from leaves to roots, indicating that the response of source-sink partitioning of assimilates in rice seedlings to LO and HO stress may be different from that induced by drought and salt stress. It may be due to the activity of sucrose transporters (SUTs) responsible for sucrose loading, was inhibited in the leaves, thereby decreasing the ability of sucrose export in the leaves. This means that the available sugar for roots was reduced, which could further limit root growth, development, and function [39]. Additionally, this could cause the accumulation of soluble sugar in leaves, which would inhibit photosynthesis [40,41]. Under the dual actions as described above, the growth and development of rice seedlings under LO and HO was inhibited, and subsequently, their rooting ability was reduced. However, further study is needed to clarify the mechanism.

\section{Conclusions}

Rhizosphere oxygen concentration significantly affected soluble sugar content as well as rooting ability of rice seedling before 3-leaf stage. When the duration is longer than one leaf age, rice seedlings under medium oxygen concentration had the strongest rooting 
ability. Like LO stress, HO treatment may also be a type of stress to rice seedlings, and its adverse effect on rice seedlings gradually appeared with prolonged treatment duration.

\section{Funding}

This work was supported by National Natural Science Foundation of China (No.31171494, No. 31701372), National Natural Foundation of Hunan Province (No. 2018JJ3583).

\section{Data Availability Statement}

All data generated or analyzed during this study are included in the article.

\section{Acknowledgments}

We would like to thank the staffs in Nanjing Zoonbio Biotechnology Co., Ltd. for advice on the data analysis.

\section{Conflicts of Interest}

The authors declare no competing interests.

\section{Bibliography}

1. Fairhurst TH and Dobermann A. In Better Crops International 16 (2002).

2. FAOSTAT. Statistical Database of the Food and Agricultural Organization of the United Nations. (2017).

3. Statistics CNBO. China Rural Statistical Yearbook (2017).

4. Bai RP. "Several issues on the route choice of mechanization of rice production technology". Chinese Agricultural Mechanization 233 (2011):15-18+22.

5. Ling L. "Study on the tillering characteristics and improvement of high-yielding cultivation techniques for machine-transplanted rice". Jiangsu Agricultural Science (2005): 14-19+126.

6. Ding CL., et al. "Study on rooting ability of rice seedlings: rooting and material dynamics of rice seedlings". Shanghai Agricultral Science (1981): 1-3+25.

7. He Q., et al. "Correlation of Rooting Traits in Seedling Stage to Activity of Root System in Late Growth Stage and Panicle Traits in Hybrid Rice". Hybrid Rice 21 (2006): 75-77.

8. Xu FX., et al. "Relationships between root growth ability and root flux activity and aerial part characteristics of hybrid mid -season rice". Southwest China Journal of Agricultural Sciences 15 (2002): 34-37.
9. Xu FX., et al. "Relationship between Rooting Ability and Drought Resistance at Full-heading in Mid-season Hybrids Rice". Acta Agronom Ica Sinica 29 (2003): 188-193.

10. Wang JJ and Tang ZH. "The Regulation of Soluble Sugars in the Growth and Development of Plants". Botanical Research (2014): 71-76.

11. Zhao JT., et al. "Research on the Role of the Soluble Sugar in the Regulation of Physiological Metabolism in Higher Plant". 34 (2006): 6423-6425 and 6427.

12. Macgregor DR., et al. "Root System Architecture in Arabidopsis Grown in Culture Is Regulated by Sucrose Uptake in the Aerial Tissues". The Plant Cell 20 (2008): 2643-2660.

13. Cheng LB., et al. "Comparative transcriptome analysis revealed the cooperative regulation of sucrose and IAA on adventitious root formation in lotus (Nelumbo nucifera Gaertn)". BMC Genomics 21 (2020).

14. Takahashi F., et al. "Sugar-induced adventitious roots in Arabidopsis seedlings". The Journal of Plant Research 116 (2003): 83-91.

15. Ogawa A., et al. "Sugar Accumulation along the Seminal Root Axis, as Affected by Osmotic Stress in Maize: A Possible Physiological Basis for Plastic Lateral Root Development". Plant Production Science 8 (2005): 173-180.

16. Ding YF., et al. "Comparison studies of roots physiology activity between rice dry seedbed seedlings and wet seedbed seedlings". Journal of Nanjing Agricultural University 24 (2001): $1-5$.

17. Zhou WL., et al. "Effect of Bast Fiber Film and Seedling Fertilizer Application Methods on Quality of Machine-transplanted Rice Seedling". Acta Agriculturae Boreali-Sinica 31 (2016): 191-197.

18. Zhou WL., et al. "Rooting ability of rice seedlings increases with higher soluble sugar content from exposure to light". PLoS ONE 15 (2020): e0241060.

19. Rosa M., et al. "Soluble Sugars-Metabolism, sensing and abiotic stress". A complex network in the life of plants. Plant Signal and Behavior 4 (2009): 388-393.

20. Lemoine R., et al. "Source-to-sink transport of sugar and regulation by environmental factors". Frontiers in Plant Science 4 (2013): 1-21. 
21. Zhao X., et al. "Review of Acclimating Mechanism to Hypoxia Condition in Rice". Crops (2015): 5-12.

22. Zhou WL., et al. "Advances in the effects of rhizosphere oxygenincreasing on rice root morphology and physiology". Chinese Journal of Eco-Agriculture 26 (2018): 367-376.

23. Mustroph A., et al. "Hypoxic Energy Metabolism and PPi as an Alternative Energy Currency". Plant Cell Monographs 21 (2014): 165-184.

24. Kawai M., et al. "Cellular dissection of the degradation pattern of cortical cell death during aerenchyma formation of rice roots". Planta 204 (1998): 277-287.

25. Wang RD and Yin JZ. "Crop cultivation". 2 edition (2015): 7680.

26. Xu CM., et al. "Effects of Low Oxygen Stress on the Root Function and Enzyme Activities Related to Nitrogen Metabolism in qRoots of Rice Seedlings". Scientia Agricultura Sinica 49 (2016): 1625-1634.

27. PezeshkI SR. "Wetland plant responses to soil flooding". Environmental and Experimental Botany 46 (2001): 299-312.

28. Xu CM., et al. "Effect of Aeration on Root Growth and Nitrogen Metabolism in Rice". Chinese Journal of Rice Science 26 (2012): 320-324.

29. Zhao F., et al. "Response of Morphological, Physiological and Yield Characteristics of Rice (Oryza sativa L.) to Different Oxygen-Increasing Patterns in Rhizosphere". Acta Agronomica Sinica 36 (2010): 303-312.

30. Hu ZH., et al. "Effects of Rhizosphere Oxygen Concentration on Rice Grain Yield and Nitrogen Utilization". Chinese Journal of Rice Science 29 (2015): 382-389.

31. Xu CM., et al. "Effects of Rhizosphere Oxygen Concentration on Nutrient Uptake and Root Morphology of Rice at Tillering Stage". Chinese Journal of Rice Science 29 (2015): 619-627.

32. Zhao F., et al. "Effect of Continuous Aeration on Growth and Activity of Enzymes Related to Nitrogen Metabolism of Different Rice Genotypes at Tillering Stag". Acta Agronomica Sinica 38 (2012): 344-351.

33. Kircher S and Schopfer P. "Photosynthetic sucrose acts as cotyledon-derived long-distance signal to control root growth during early seedling development in Arabidopsis". Proceedings of the National Academy of Sciences 109.28 (2012): 1121711212.
34. Kutschera U and Briggs WR. "Photomorphogenesis of the root system in developing sunflower seedlings: a role for sucrose". Plant Biology 21 (2019): 627-633.

35. Xu W., et al. "Drought stress condition increases root to shoot ratio via alteration of carbohydrate partitioning and enzymatic activity in rice seedlings". Acta Physiologiae Plantarum 37 (2015): 1-11.

36. Dubey RS and Singh AK. "Salinity induces accumulation of soluble sugars and alters the activity of sugar metabolising enzymes in rice plants". Biologia Plantarum 42 (1999): 233-239.

37. Verma S and Dubey RS. "Effect of cadmium on soluble sugars and enzymes of their metabolism in rice". Biologia Plantarum 44 (2001): 117-123.

38. Hisashi KN., et al. "Soluble sugar availability of aerobically germinated barley, oat and rice coleoptiles in anoxia". Journal of Plant Physiology 167 (2010): 1571-1576.

39. Zhang Q., et al. "Environmental factors constraining adventitious root formation during flooding of Solanum dulcamara". Functional Plant Biology 44 (2017): 858-866.

40. Paul MJ and Pellny TK. "Carbon metabolite feedback regulation of leaf photosynthesis and development". Journal of Experimental Botany 54 (2003): 539-547.

41. Araya T., et al. "Effects of carbohydrate accumulation on photosynthesis differ between sink and source leaves of Phaseolus vulgaris L". Plant and Cell Physiology 47 (2006): 644-652.

42. Pound MP., et al. "RootNav: Navigating images of complex root architectures”. Plant Physiology 162 (2013): 1802-1814.

43. Lee HS. "Principles and techniques of plant physiological biochemical experiment". American Journal of Plant Sciences 5.20 (2005).

\section{Volume 5 Issue 12 December 2021 (C) All rights are reserved by Jing Chen., et al.}

